\title{
INVESTIGACIONES
}

\section{SATISFACCIÓN CON LA PROFESIÓN DE PROFESOR DE ENSEÑANZA SECUNDARIA EN PORTUGAL}

JOB SATISFACTION AMONG PORTUGUESE SECONDARY TEACHERS A SATISFAÇÃO COM A PROFISSÃO EM PROFESSORES DO ENSINO
SECUNDARIO EM PORTUGAL

\author{
María Figeiredo* \\ Universidade Moderna, de Lisboa \\ Victor Álvarez Rojo** \\ Universidad de Sevilla
}

\section{RESUMEN}

Este es un estudio mediante encuesta, de carácter exploratorio-descriptivo, cuya finalidad es delimitar un perfil transversal a la profesión de profesor de Enseñanza Secundaria que defina la satisfacción con la práctica diaria de la docencia. Hemos tenido en cuenta una muestra de 524 profesores de Enseñanza Secundaria en Portugal Continental, a los que se les aplicaron entre diciembre del 2006 y julio de 2007 tres instrumentos de medida: (1) una encuesta de información sociodemográfica, (2) una encuesta de fuentes de bienestar y de satisfacción con la profesión de docente y (3) una escala numérica de perfil de satisfacción de los profesores con su profesión. Los datos obtenidos revelan niveles muy significativos de insatisfacción en este grupo de profesionales de la enseñanza.

Palabras clave: Satisfacción profesional, profesorado de Enseñanza Secundaria.

\footnotetext{
* Doutoranda no programa de doctorado de Didáctica y Organización de las Instituciones Educativas en la Universidad de Sevilla, Psicóloga Clínica, Psicopedagoga, Pós-graduada em Psicologia da Saúde, Professora Convidada na Licenciatura de Psicopedagogia da Universidade Moderna de Lisboa e na Pós-graduação em Necessidades Educativas Especiais no Instituto Superior de Ciências da Informação e Administração, de Aveiro; linhas de investigação: Perfil de Satisfação e Necessidades de Formação dos Professores Universitários Portugueses no Espaço Europeu de Educação Superior. Correo-E: psi.mariafigueiredo@gmail.com

** Doctor en Pedagogía y profesor del Dpto. MIDE de la Facultad de Ciencias de la Educación de la Universidad de Sevilla, impartiendo docencia en siciplinas relacionados con la orientación, la gestión de la calidad y el diseño de programas de intervención socioeducativa. Las lineas de investigación en las que se ha centrado en los úiltimos años han sido: a) la docencia, la orientación y la gestión de la calidad en el ámbito universitario y b) la evaluación de los aprendizajes.
} 


\begin{abstract}
This work tries to describe the different dimensions of job satisfaction among secondary education teachers in Continental Portugal. A survey research has been conducted from December 2006 to July 2007 among 524 teachers of several administrative districts (Setúbal, Aveiro, Viseu, Coimbra e Leiria). Data collection was done applying the following set of techniques: 2 questionaire-bassed surveys - a socio-demographic one and another on job-satisfacción perceptions; and a numerical scale in order to define a job satisfaction profile. Among most significant findings of the present research stands the wide level of disatisfaction with the teaching profession as a central perception of this group of teachers.
\end{abstract}

Key words: Job satisfaction, secondary education teachers.

\title{
Introdução
}

O termo Bem-estar lembra-nos conceitos como felicidade, optimismo, vitalidade, satisfação com a vida, alegria. Uns são conceitos que se encaixam na perspectiva hedonica, felicidade, experiências de prazer, todas as experiências de satisfação com a vida, outros conformam a perspectiva eudemonica ou de bem-estar psicológico, desenvolvimento pessoal, agir de acordo com valores próprios, auto-determinação, motivação intrínseca e expressividade pessoal (Carruthers, 2004). Bem-estar subjectivo é um aspecto do bem-estar psicológico, necessário mas não suficiente para um indivíduo estar bem com a vida. Diferentes autores (Albuquerque \& Tróccoli, 2004) evocam consensualmente, o conceito de bem-estar subjectivo, em dimensões separadas mas relacionadas (Diener, Lyubomirsky \& King, 2005), uma cognitiva e outra afectiva, onde se conceptualiza a satisfação com a vida e mesmo o sentimento de felicidade, no modelo dimensional tripartido, de: (1) A satisfação global com a vida, dimensão de julgamento cognitivo sobre algum domínio particular da própria vida, comparando as circunstâncias de vida reais e um outro qualquer padrão ideal, ou seja, uma avaliação sobre a vida de acordo com valores próprios; (2) $\mathrm{O}$ afecto positivo, que é um sentimento hedónico experimentado num determinado momento, como um entusiasmo, interesse, alegria, felicidade ou prazer activo, mais emocional do que cognitivo; (3) $\mathrm{O}$ afecto negativo, como sendo um estado transitório de emoções desagradáveis, como tristeza, aborrecimento, angústia, depressão, perda, ansiedade, inquietação ou outros sintomas aflitivos (Albuquerque \& Tróccoli, 2004).

Relativamente à satisfação com a profissão de professor (profissão de substrato relacional ou "emotional labor") importa compreender como se estabelece a relação positiva entre satisfação no trabalho e satisfação com a vida em geral, se bem que são escassos e recentes os estudos sobre esta relação no grupo dos professores. A relação educativa professor-aluno, tradicionalmente, estruturava-se sobre uma relação assimétrica em que o professor era o responsável pelos alunos e o detentor do poder do saber.

O conceito de "emotional labour" (Soares, 2003) entende a profissão de professor como uma profissão de "substrato emocional", i.e., em que se tem essencialmente de vivenciar, gerir e compreender emoções, onde é tão importante fazê-lo com as próprias emoções, como as dos outros que connosco partilham esse contexto, para que sejam providenciadas as adequadas respostas às regras e normas institucionais (Chu, 2002).

Os professores constituem um dos maiores grupos profissionais e um dos mais qualificados, do ponto de vista académico. Utilizando o poder metafórico de Hameline, D. (Nó- 
voa, 1999) qualificamos o professor como um conhecedor que em primeiro lugar é um doctus, aquele que revela com prazer a sua ciência, um peritus, o que tem qualidades especiais para fazer algo e, ainda, um sapiens, aquele que depois de realizar uma acção continua a apreciá-la para a aperfeiçoar. A acção docente na sua especificidade afirma-se por profissionalidade, ou seja, pelo conjunto de comportamentos, de conhecimentos, de habilidades, de atitudes e valores.

Neste trabalho assume-se a escolha de um modelo de investigação salutogénica que fomos buscar à Psicologia Positiva (Seligman, 2000) a qual tem como objectivo trazer novos conhecimentos sobre o funcionamento da psique humana, para ajudar a resolver problemas de saúde mental mas, também, numa tentativa de alcançar o saber sobre melhores comportamentos de qualidade e bem-estar para a vida em geral.

De acordo com Seligman, (2002) a Psicologia Positiva baseia-se em três pilares:

(1) O estudo da emoção positiva,

(2) $O$ estudo dos traços e qualidades positivas, sobretudo forças e virtudes, incluindo inteligência e capacidades físicas e

(3) O estudo das instituições positivas como a democracia, a família ou a liberdade. Com base nesse modelo escolheram-se instrumentos de medida e definição de perfil e a metodologia de análise de dados.

\section{Metodo}

O objectivo geral desta investigação é encontrar um perfil transversal à profissão de professor que defina a satisfação com a prática diária da docência.

QUADRO 1. Objectivos de investigação.

\begin{tabular}{|l|l|}
\hline OBJECTIVO GERAL & \multicolumn{1}{c|}{ OBJECTIVOS ESPECÍfICOS } \\
\hline $\begin{array}{l}\text { Caracterizar um perfil } \\
\text { de satisfação profis- } \\
\text { sional dos professores } \\
\text { do ensino secundário, } \\
\text { com os dados obtidos } \\
\text { e avaliados }\end{array}$ & $\begin{array}{l}\text { Identificar percepções dos professores do ensino secundário sobre a sua } \\
\text { satisfação profissional; para obter informações qualitativas sobre a reali- } \\
\text { dade docente portuguesa }\end{array}$ \\
\cline { 2 - 2 } & $\begin{array}{l}\text { Avaliar diferentes níveis de bem-estar subjectivo e de satisfação profis- } \\
\text { sional, por dimensões; para conhecer objectivamente as situações induto- } \\
\text { ras de satisfação no e com o desempenho profissional, correlacionando } \\
\text { categorias que estejam enquadradas numa moldura de bem-estar subjec- } \\
\text { tivo e sentido como positivo com a vida profissional }\end{array}$ \\
\cline { 2 - 2 } & $\begin{array}{l}\text { Definir um perfil do professor do ensino secundário em termos de satis- } \\
\text { fação com a sua profissão }\end{array}$ \\
\hline
\end{tabular}

Aborda-se a descoberta e exploração de factores respeitantes ao comportamento docente e todo um conjunto de afectos positivos, de bem-estar e de satisfação generalizada e vivida com a profissão. Desenvolve-se um estudo do tipo exploratório descritivo, com um desenho tipo "survey", mediante questionários e escalas de valor. No quadro 2 apresentam-se as variáveis de investigação. 
QUADRO 2. Variáveis e investigação.

\begin{tabular}{|c|c|c|}
\hline DIMENSÕES & VARIÁVEIS & TIPOLOGIA \\
\hline \multirow{16}{*}{ 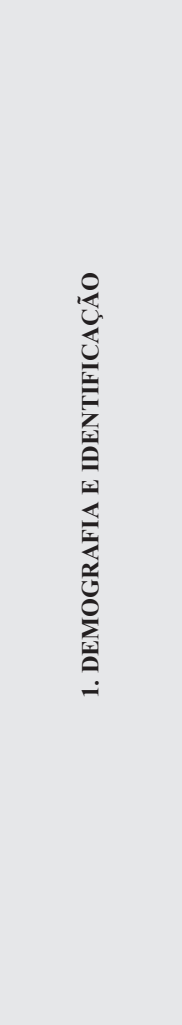 } & Sexo & Masculino e feminino \\
\hline & Idade & \\
\hline & Estado civil & solteiro, casado/união de facto, separado/divorciado, viúvo \\
\hline & Número de filhos & \\
\hline & Habilitações académicas & $\begin{array}{l}\text { bacharelato, licenciatura, pós-graduação, mestrado, } \\
\text { doutoramento }\end{array}$ \\
\hline & Anos de serviço & \\
\hline & Tipo de escola & pública, privada \\
\hline & $\begin{array}{l}\text { Localização geográfica da } \\
\text { escola }\end{array}$ & distrito, concelho \\
\hline & Grupo disciplinar & em anexo \\
\hline & Vínculo laboral & $\begin{array}{l}\text { nomeação definitiva/quadro escola, nomeação definitiva/ } \\
\text { quadro zona pedagógica, contratado/profissionalizado, } \\
\text { contratado/não-profissionalizado, estagiários/ramo } \\
\text { educacional, estagiários/estágio pedagógico }\end{array}$ \\
\hline & $\begin{array}{l}\text { Desempenho de outros cargos } \\
\text { na escola }\end{array}$ & $\begin{array}{l}\text { órgãos de gestão, director de turma, coordenador de grupo } \\
\text { disciplinar, outros cargos }\end{array}$ \\
\hline & Número de alunos da escola & \\
\hline & $\begin{array}{l}\text { Horário lectivo sem. no } \\
\text { presente ano }\end{array}$ & $\begin{array}{l}\text { horário reduzido, menos de } 6 \text { horas, } 6 \text { a } 11 \text { horas, } 12 \text { a } 22 \\
\text { h., mais de } 22 \mathrm{~h}\end{array}$ \\
\hline & $\begin{array}{l}\text { Anos em que não conseguiu } \\
\text { colocação }\end{array}$ & 1 ano, 2 anos, 3 anos, mais de 3 anos, sempre colocado \\
\hline & $\begin{array}{l}\text { Mudança de domicílio para a } \\
\text { prática docente }\end{array}$ & sim ou não \\
\hline & $\begin{array}{l}\text { Pessoas com quem vive } \\
\text { durante o período de aulas }\end{array}$ & \\
\hline \multirow{4}{*}{ 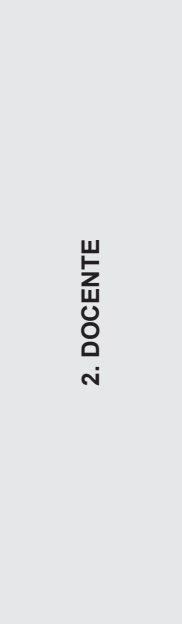 } & $\begin{array}{l}\text { Relacionamentos } \\
\text { interpessoais - "emotional } \\
\text { labor" ou profissão de substrato } \\
\text { relacional }\end{array}$ & $\begin{array}{l}\text { (Hargraaves, 1999, citado por Seco, 2002): concepção da } \\
\text { profissão cuja especificidade é ser desempenhada com e } \\
\text { para pessoas; comunicação, amizade, convívio, bem-estar } \\
\text { relacional e colaborativo }\end{array}$ \\
\hline & Actividades pedagógicas & $\begin{array}{l}\text { Possibilidade de desenvolvimento profissional divergente } \\
\text { que toma forma nas actividades que dão sentido de } \\
\text { envolvimento em várias competências docentes; trabalho } \\
\text { de equipa; desenvolvimento do conhecimento prático e } \\
\text { subjectivo }\end{array}$ \\
\hline & Reconhecimento profissional & $\begin{array}{l}\text { percepção do impacto positivo que o desempenho de } \\
\text { competências profissionais tem sobre esferas relacionais } \\
\text { directamente implicadas nesta dimensão social; } \\
\text { manifestações de apreço pelo trabalho bem realizado pelos } \\
\text { alunos, comunidade, encarregados de educação e pares, e } \\
\text { retribuições salariais ou de estatuto social; reforços } \\
\text { positivos comunicacionais; boas condições para o } \\
\text { desempenho das funções ou, ainda, possibilidades de } \\
\text { progressão na carreira }\end{array}$ \\
\hline & Segurança & $\begin{array}{l}\text { características do trabalho que promovem estabilidade } \\
\text { económica }\end{array}$ \\
\hline
\end{tabular}




\begin{tabular}{|c|c|c|}
\hline DIMENSÕES & VARIÁVEIS & TIPOLOGIA \\
\hline \multirow{5}{*}{  } & O sucesso dos alunos & $\begin{array}{l}\text { Segundo Gilly (1976) citado por Jesus (1998), que fez in- } \\
\text { vestigações na área das representações recíprocas dos } \\
\text { professores e alunos, os docentes privilegiam essencial- } \\
\text { mente a componente cognitiva dos alunos e o seu desen- } \\
\text { volvimento global tanto a nível escolar, como individual e } \\
\text { motivacional }\end{array}$ \\
\hline & Características dos alunos & $\begin{array}{l}\text { denominadores pessoais e relacionais que distinguem cada } \\
\text { um dos alunos aos olhos dos professores e nas suas vivên- } \\
\text { cias diárias pessoais, afectivo-relacionais e de trabalho }\end{array}$ \\
\hline & $\begin{array}{l}\text { A escola como instituição de } \\
\text { trabalho }\end{array}$ & $\begin{array}{l}\text { a gestão institucional, a estrutura interna, a estrutura física, } \\
\text { os materiais de apoio, a localização geográfica, profissiona- } \\
\text { lismo, instalações físicas, material de apoio pedagógico, } \\
\text { horários, tamanhos das turmas }\end{array}$ \\
\hline & $\begin{array}{l}\text { Crescimento pessoal e profis- } \\
\text { sional }\end{array}$ & $\begin{array}{l}\text { inputs intrínsecos e/ou extrínsecos ao indivíduo que o im- } \\
\text { pelem a realizar as suas competências, continuamente, ao } \\
\text { longo do tempo, e criativamente apesar das dificuldades } \\
\text { que encontre; desejos de desenvolvimento da prática pro- } \\
\text { fissional com formação ao longo da vida; satisfação profis- } \\
\text { sional, auto-realização, sentimento de conhecimento e } \\
\text { aprendizagem contínua }\end{array}$ \\
\hline & Valores éticos & $\begin{array}{l}\text { mapeamento interno de crenças e valores que definem } \\
\text { individualmente a estrutura da profissão; valores como res- } \\
\text { peito, idoneidade, obediência, regras sociais ou disciplina }\end{array}$ \\
\hline
\end{tabular}

Amostra. O sistema administrativo escolar português organiza-se por cinco divisões regionais que correspondem a áreas geográficas: Norte, Centro, Lisboa, Sul e Ilhas. O sistema educativo português está centralizado no Ministério da Educação, o qual é responsável pela elaboração e aplicação das políticas educativas. Pretende-se retirar conclusões sobre o grande $\mathrm{n}^{\circ}$ de indivíduos que em Portugal são professores do ensino secundário $(38529$, dados preliminares 2004-05 do Ministério da Educação), utilizando para isso o universo de professores do distrito de Setúbal ( $1^{\text {a }}$ fase) e dos distritos de Aveiro, Viseu, Coimbra e Leiria ( $2^{\mathrm{a}}$ fase). O trabalho de campo decorreu durante o $3^{\mathrm{o}}$ período lectivo do ano escolar 20062007, na $1^{\text {a }}$ fase, entre Dezembro de 2006 e Abril de 2007, e consistiu na passagem do Inquérito de Informação Sociodemográfica e no Questionário de Fontes de Bem-estar e de Satisfação, e entre Junho e Julho de 2007, na $2^{\text {a }}$ fase, tempo de entrega e recolha do último instrumento de trabalho, a Escala de Satisfação com a Profissão para Professores. A entrega e recolha dos questionários foi mediada pelos Conselhos Executivos das escolas e pelos coordenadores de áreas, e entregue nas reuniões que iam tendo lugar durante aquele período lectivo. No total, participaram nesta investigação 524 indivíduos, 305 na $1^{\mathrm{a}}$ fase e 219 na $2^{\mathrm{a}}$ fase, todos professores, de diferentes idades e estados civis, mulheres e homens, efectivos e não-efectivos, a iniciarem a carreira ou em desenvolvimento, de todo o conjunto de grupos disciplinares, do $10^{\circ}$ ao $12^{\circ}$ ano escolar, acumulando ou não outros cargos na escola, entre outras diferenças ou partilhas de situações que caracterizam todos e cada um dos professores participantes. Como critérios de inclusão/exclusão refere-se que: se (1) Incluíram os indivíduos cuja actividade profissional seja a docência, no ensino secundário e não se incluíram os indivíduos que não aceitaram participar nele, sejam quais forem as suas razões; (2) que a passagem das escalas se efectuou no decurso do ano lectivo 2006/2007, (3) e que decorreu num espaço cronológico entre Dezembro de 2006 e Julho de 2007, período de tempo 
cujos limites correram em função da maior ou menor disponibilidade dos professores participantes.

Instrumentos de recolha de dados. Para a concretização do objectivo geral do estudo, construir um perfil de satisfação profissional dos professores do ensino secundário, foram desenvolvidos e aplicados e três instrumentos de recolha de dados.

I. Um inquérito de informação sociodemográfica

II. Um questionário de fontes de bem-estar e de satisfação com a profissão de docente, com uma só pergunta aberta, o Questionário de Fontes de Bem-estar e de Satisfação

III. Uma escala numérica de perfil de satisfação dos professores com a sua profissão, a Escala de Satisfação com a Profissão de Professor

Para a obtenção de dados de identificação amostral considerou-se importante o desenho de um inquérito de informação sociodemográfica, cujas 17 questões têm a ver com os dados únicos de cada indivíduo nos seus contextos pessoais e profissionais.

O questionário de fontes de bem-estar e de satisfação com a profissão de docente, com uma só pergunta aberta, foi construído para que se extraíssem das respostas fornecidas as dimensões valorizadas pelos professores sobre a sua satisfação com a prática docente, as quais nos permitiram construir algumas das perguntas consideradas pertinentes e essenciais numa escala de perfil, mas que faltavam, apesar das fontes de apoio ao desenvolvimento da nossa escala de perfil. Seguindo um modelo dedutivo de análise de conteúdo das respostas partiu-se do enquadramento teórico para a análise e conclusões, com as respostas qualitativas a serem divididas em unidades de análise, as quais foram assim agrupadas em categorias dimensionais de características formais partilhadas. Este foi um dos dois instrumentos, aplicados na $1^{\mathrm{a}}$ fase de estudo, que permitiu avançar para a construção da requerida escala de satisfação com a profissão de professor. A Escala de Perfil é composta por 33 itens e está dividida em módulos que designámos por dimensões. Cada dimensão, que não é directamente observável mas sim definida através de um conjunto de outras variáveis (itens), denomina-se por variável latente (Hill \& Hill, 2000) e é constituída por uma temática em particular, a qual corresponde aos factores de maior importância de bem-estar e de satisfação com a profissão. Utilizou-se uma escala numérica de resposta de tipo Likert de seis pontos cuja formatação prevê que os respondentes assinalem uma opção de resposta, entre 1 e 6, o equivalente entre "Completamente insatisfatório" e "Plenamente satisfatório". A Escala de Perfil permitiu-nos determinar 5 dimensões de relevante importância para o desempenho da profissão de professor com satisfação e bem-estar:

1. Profissão (Profissão de substrato relacional)

2. Aprendizagem (Aprendizagem contínua)

3. Instituição (Instituição de trabalho)

4. Reconhecimento (Reconhecimento de alunos e professores)

5. Empenhamento (Empenhamento na docência)

Da análise do valor médio obtido para as 5 variáveis pode-se afirmar que a satisfação profissional dos professores do ensino secundário é muito baixa, principalmente na satisfação com o que se relaciona com a aprendizagem ao longo da carreira profissional. 


\section{Resultados}

Identificámos percepções tendencialmente negativas na sua carga emocional e grandes dificuldades para referenciar emoções positivas. Chegámos às respostas pretendidas, resultado das perguntas de investigação, cujo domínio principal se prende com o perfil de satisfação profissional dos professores do ensino secundário. Apresentam-se agora alguns dos principais resultados:

As "Idades" apresentam um comportamento idêntico, quer se trate de professores do género feminino, quer do masculino. Verifica-se uma maior amplitude nas idades das professoras em que os indivíduos mais jovens e os mais idosos são do sexo feminino.

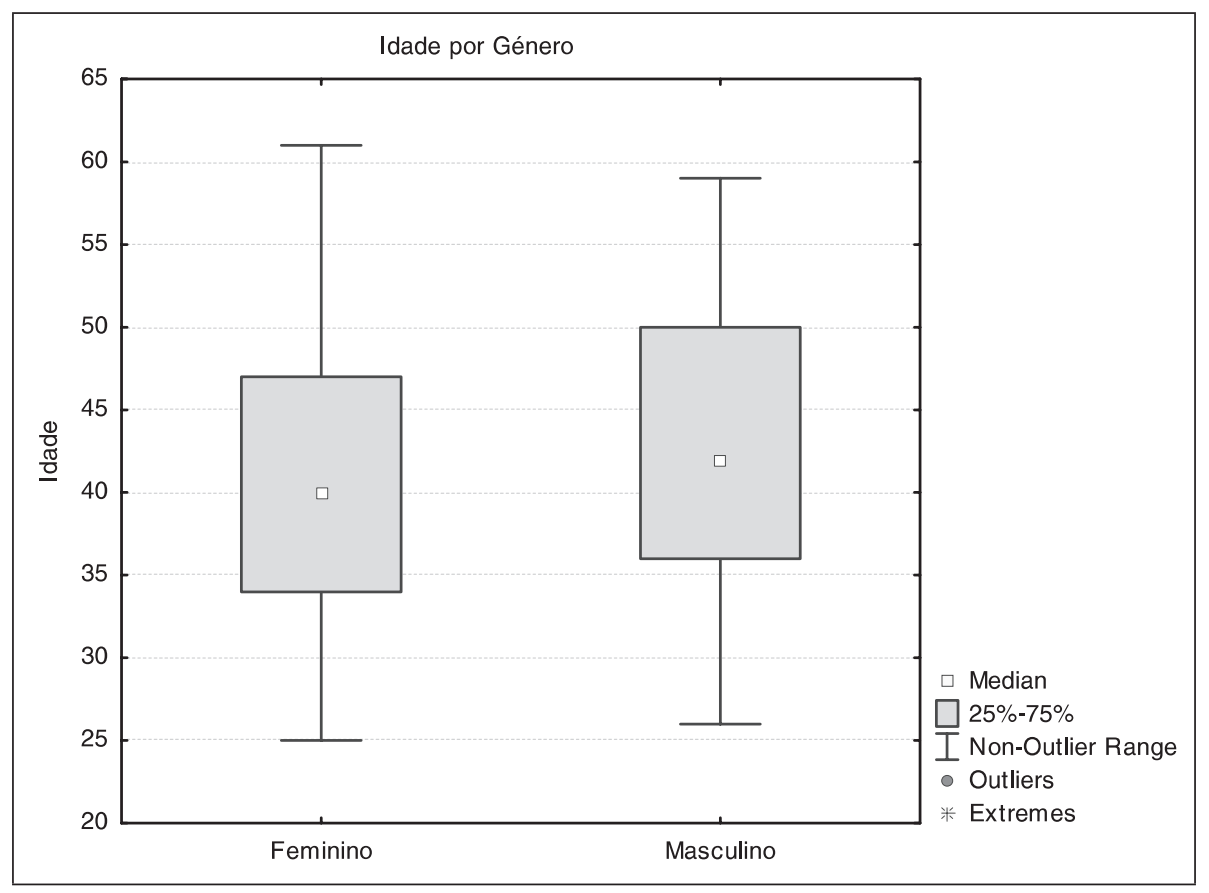

GRÁFICO 1.

Distribución de la edad por género.

Os inquiridos do "Género" masculino possuem habilitações académicas superiores aos do género feminino, falamos de cerca de $30 \%$ contra 17 . É no grupo masculino que está a grande parte dos inquiridos com bacharelato.

Como é esperado, existe uma relação forte e positiva entre a idade e o número de anos ao serviço de docência; quanto mais idade tem o docente maior é o número de anos ao serviço, daí que no gráfico 3 as observações se encontrem concentradas perto da recta que permitiria escrever a relação matemática entre as duas variáveis. Tal relação pode ser confirmada pelo coeficiente de correlação (indicador estatístico que permite identificar a existência e tipo de relação entre variáveis) que apresenta um valor de 0,91. 


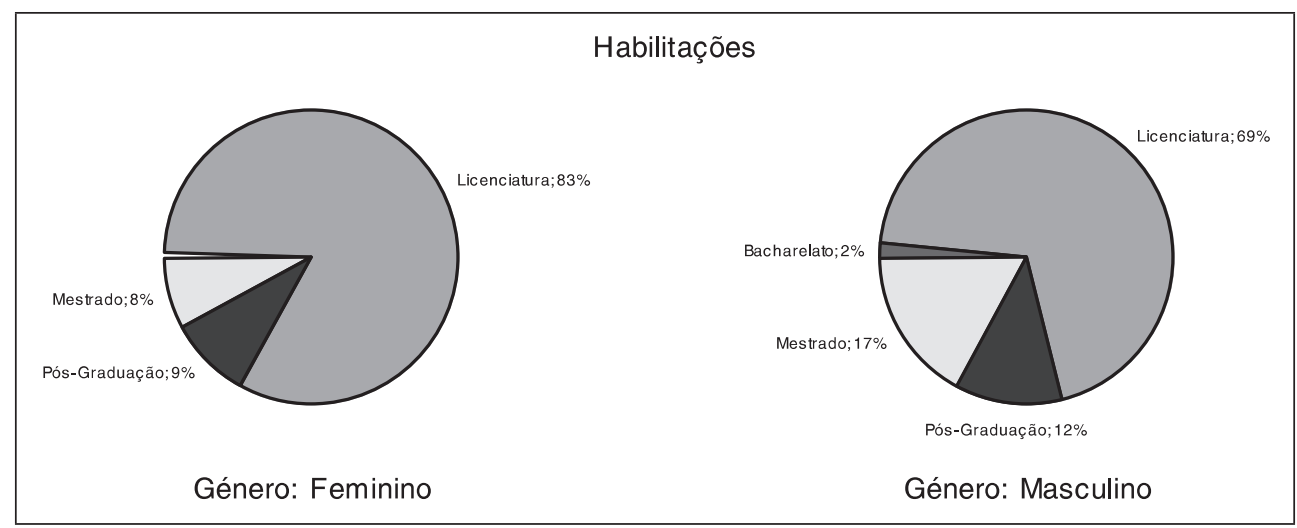

GRÁFICO 2.

Habilitaciones vs Sexo.

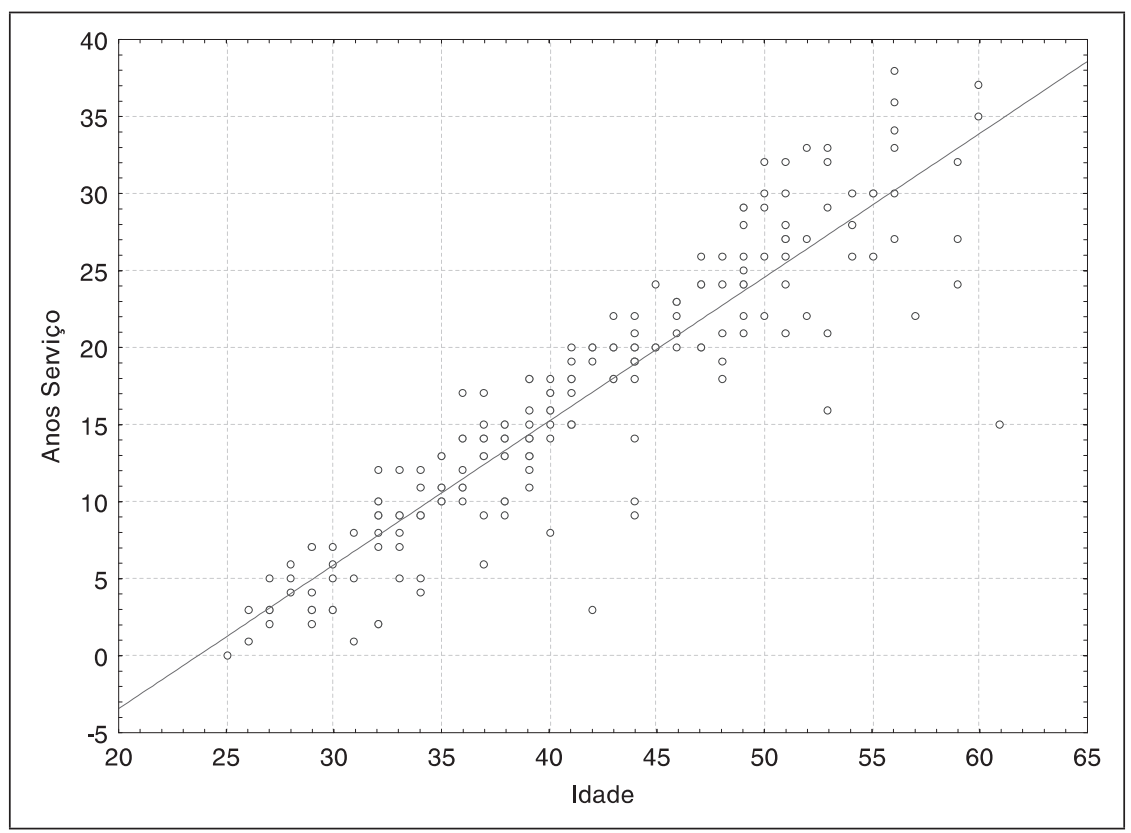

GRÁFICO 3.

Relación entre la edad y los años de servicio docente.

Confirmaram-se um conjunto itens aceitáveis como instrumentos de medida, com nenhum dos critérios a apresentar valores de rejeição, o que possibilitou proceder à interpretação de cada uma das variáveis latentes, quadro 3, para que a sua clara identificação. 
QUADRO 3. Ítems aceptes como instrumentos de medida.

\begin{tabular}{|c|c|c|c|c|}
\hline $\begin{array}{l}\text { PROFESIÓN DE } \\
\text { SUSTRATO } \\
\text { RELACIONAL }\end{array}$ & $\begin{array}{l}\text { APRENDIZAJE } \\
\text { CONTINUA }\end{array}$ & $\begin{array}{l}\text { INSTITUCIÓN DE } \\
\text { TRABAJO }\end{array}$ & $\begin{array}{l}\text { RECONOCIMIENTO } \\
\text { DE ALUMNOS Y } \\
\text { FAMILIARES }\end{array}$ & $\begin{array}{l}\text { EMPEÑAMIENTO } \\
\text { EN LA DOCENCIA }\end{array}$ \\
\hline Profissão & $\begin{array}{l}\text { Estatuto } \\
\text { socioprofissional }\end{array}$ & $\begin{array}{l}\text { Reconhecimento } \\
\text { pelos Superiores } \\
\text { Hierárquicos }\end{array}$ & Respeito & $\begin{array}{l}\text { Participação na } \\
\text { formação dos alunos }\end{array}$ \\
\hline Aprendizagem & $\begin{array}{l}\text { Progressão na } \\
\text { carreira }\end{array}$ & Instalações & $\begin{array}{l}\text { Reconhecimento dos } \\
\text { alunos }\end{array}$ & Partilha com Alunos \\
\hline $\begin{array}{l}\text { Reconhecimento } \\
\text { dos pares }\end{array}$ & Promoção & Horários & Alunos & Motivação \\
\hline Trabalho equipa & Salário & $\begin{array}{l}\text { Acesso a materiais } \\
\text { Pedagógicos }\end{array}$ & $\begin{array}{l}\text { Empenhamento nas } \\
\text { aprendizagens }\end{array}$ & $\begin{array}{l}\text { Projectos } \\
\text { desenvolvimento }\end{array}$ \\
\hline $\begin{array}{l}\text { Desempenho } \\
\text { Profissional }\end{array}$ & $\begin{array}{l}\text { Aumentos } \\
\text { Salariais }\end{array}$ & Políticas de Gestão & & \\
\hline $\begin{array}{l}\text { Relacionamento } \\
\text { Pessoal }\end{array}$ & Competências & Condições físicas & & \\
\hline $\begin{array}{l}\text { Vivências } \\
\text { Interpessoais }\end{array}$ & Políticas & & & \\
\hline $\begin{array}{l}\text { Relações de } \\
\text { Amizade }\end{array}$ & Estabilidade & & & \\
\hline $\begin{array}{l}\text { Tamanho das } \\
\text { Turmas }\end{array}$ & & & & \\
\hline
\end{tabular}

Da análise do valor médio obtido para as 5 variáveis, tabela 1 , pode-se afirmar que a satisfação profissional dos professores do ensino secundário é muito baixa, principalmente na satisfação com o que se relaciona com a aprendizagem ao longo da carreira profissional.

TABELA 1. Indicadores estadísticos de las nuevas variables.

\begin{tabular}{|l|c|c|c|c|c|c|c|}
\hline \multicolumn{1}{|c|}{ Variável } & Valid N & Média & Sum & Mínimo & Máximo & $\begin{array}{c}\text { Std. } \\
\text { Dev. }\end{array}$ & $\begin{array}{c}\text { Coef. } \\
\text { Var. }\end{array}$ \\
\hline Profissão & 205 & 3,407 & 698,444 & 1,000 & 5,333 & 0,754 & 0,221 \\
\hline Aprendizagem & 203 & 2,261 & 459,125 & 1,000 & 4,375 & 0,757 & 0,334 \\
\hline Instituição & 212 & 3,357 & 711,833 & 1,000 & 5,833 & 0,932 & 0,277 \\
\hline Reconhecimento & 208 & 3,233 & 672,500 & 1,000 & 5,750 & 0,818 & 0,253 \\
\hline Empenhamento & 210 & 3,430 & 720,500 & 1,000 & 5,500 & 0,828 & 0,241 \\
\hline
\end{tabular}




\section{Discussão de resultados}

Destacam-se algumas conclusões sobre as quais poderemos reflectir do seguinte modo:

\section{(Como é que os professores definem a satisfação profissional?)}

Os professores negam sentirem-se satisfeitos com a sua profissão. Esta é, sempre, a primeira e mais afirmativa posição, se bem que com as várias e diferentes avaliações levadas a cabo no nosso estudo, foi possível encontrar influências diferentes, mais ou menos altas, sobre a satisfação profissional.

(Quais são os elementos, psicológicos, contextuais e relacionais, implicados na satisfação profissional?)

O facto de identificarmos algumas percepções desta classe profissional permitiu-nos distinguir quais as dimensões mais importantes e que mais influenciam os professores na sua satisfação profissional, para figurarem num perfil. Falamos de cinco dimensões de carácter psicossocial e que congregam: (1) A profissão específica de professor que é uma profissão de substrato emocional; (2) O factor aprendizagem que não pára de acontecer ao longo do tempo profissional, tanto para quem aprende, como para quem ensina; (3) A escola como instituição de trabalho especial e específica, por ser um tecido organizacional vivo e em constante mudança, que o é através dos professores; especial porque ensina a crescer com tudo o que ensina, de todas as formas que prepara as crianças a serem adultos; não há outra instituição que tenha esse papel, embora todas funcionem com pessoas e para as pessoas; específica porque tem um papel e uma função social única, a função social que transforma a face da economia de um país, pelo potencial humano que forma; e é nesta função que reside o seu maior risco se os seus elementos constituintes perderem qualidades; é o risco do insucesso generalizado, de resultados tão amplos como destruidores do papel de uma sociedade moderna e em crescimento; (4) A necessidade básica específica de reconhecimento, pessoal, social e profissional, e (5) Toda a dinâmica absolutamente necessária de empenhamento e envolvimento na prática docente, ano após ano, turma após turma, e que se define como intrínseco para ser eficaz.

\section{(Quais as diferenças nos níveis de satisfação dos professores do ensino secundário?)}

Encontrámos um conjunto de características socioprofissionais que nos permite descrever diferentes níveis de satisfação com a docência. Começamos por referir um aspecto de conjunto que nos revela que a maioria dos docentes do ensino secundário se caracteriza pela maturidade e por características psicossociais de uma certa estabilidade, o que está de acordo com sendo que se toma como certo que a idade trás experiências úteis nas tomadas de decisões e nas motivações para os vários papéis de vida a desempenhar e que todos estes desenhos e percursos individuais são mensageiros de estabilidade suficiente para a gestão dos projectos propostos. Mas também nos leva a concluir que os jovens profissionais e aqueles que estão no último quarto da carreira se sentem insatisfeitos e desmobilizados da 
sua participação dinâmica na instituição escola. É natural que a criatividade da inovação e a experiência ponderada, de uns e outros, não esteja a ser aproveitada no ensino e nas suas necessidades urgentes e actuais, nem seja seu apanágio. Os homens e os professores com menos anos de carreira estão mais satisfeitos mas se tiverem outro cargo na escola, para além da docência, o nível de satisfação também aumenta. Ser do departamento de Expressões é estar mais satisfeito mas ser do departamento de Línguas é estar mais insatisfeito.

(Quais as diferenças nos níveis de satisfação dos professores do ensino secundário relacionadas com factores psicológicos, contextuais e relacionais, i.e., psicossociais?)

Ainda sobre as referidas cinco dimensões e olhando para as diferenças entre si, podemos apontar o que de seguida se descreve. A profissão (1) de professor é uma profissão de acção social cuja especificidade tem a ver com as relações privilegiadas que se constroem e que estão fundamentalmente assentes exactamente nessa relação do professor com o aluno. É a partir daqui que se desenrolam as aprendizagens e o crescimento dos alunos. Portanto, estamos num domínio eminentemente relacional, o qual também diz respeito ao conjunto de factores reunidos em torno do reconhecimento (4), necessidade básica humana, que é o processamento da informação recebida do exterior sobre o desempenho próprio e que vai no sentido do ideal de perfeito, de correcto ou de bom que pelo seu carácter abrangente sobre o sentimento de reconhecimento, é uma dimensão de influência relacional mas também psicológica, logo, podemos dizer que este é um domínio psico-relacional. Como domínio psicológico salienta-se a dimensão empenhamento (5) que encerra desde processos psicológicos intrínsecos, como aqueles que estão ligados à motivação para ensinar e ao prazer de se ver envolvido em projectos pedagógicos o que nos dá elementos muito importantes sobre questões estruturais do indivíduo que têm a ver com aquilo que é mais importante para que a docência seja uma profissão de satisfações várias de vida. Os dois restantes domínios que completam a constituição do perfil de satisfação com a profissão são relacionados com factores contextuais. Referimo-nos à aprendizagem (2) que esta profissão específica obriga e proporciona numa dupla interacção renovada continuamente e, só assim, sendo possível ascender na carreira e usufruir de mais benefícios materiais. E, também, à instituição de trabalho (3), a escola, com estruturas organizativas e com dinâmicas específicas, já que os seus clientes não são completamente autónomos, pelo que trazem a família para dentro das suas fronteiras, e precisam dos professores-prestadores como modelos de vida profissional e pessoal para além dos saberes que veiculam.

(Quais os elementos de maior importância que devem figurar num perfil de satisfação profissional dos professores do ensino secundário?)

Tendo em conta em conta as cinco dimensões de perfil seria possível dizer que a satisfação com a docência advém, principalmente, do facto de ser uma profissão de substrato relacional, desenvolvida numa organização de trabalho tão específica que não tem par, e concordante com factores motivacionais intrínsecos dirigidos para o desenvolvimento do saber. 


\section{(Quais os níveis de bem-estar subjectivo dos professores do ensino secundário?)}

O perfil de satisfação com a profissão abrange tanto factores conceptuais do domínio psicológico, como de domínios subjectivos. Salvaguardando a necessidade de estudos mais aprofundados sobre esta divisão conceptual, com o presente estudo, é possível ponderar na articulação das duas medidas de bem-estar, psicológico e subjectivo, num conceito de consensualidade que permita diminuir as dificuldades da sua definição. Bem porque o conceito de bem-estar subjectivo já comporta uma dimensão cognitiva, de avaliação sobre a vida, de acordo com valores idealizados e que se denomina de satisfação global com a vida e, uma outra dimensão que se estende a uma dialéctica afectiva, a qual se constitui por sentimentos positivos experimentados mas também por afectos negativos transitórios. Tendo em conta que o bem-estar subjectivo integra as dimensões cognitiva e afectiva, no nosso estudo e face aos resultados encontrados, referimos níveis baixos de bem-estar subjectivo e, principalmente, níveis polarizados de afectos negativos, não transitórios, e juízos avaliativos negativos sobre a satisfação com a profissão docente. Neste caso, não é possível falar de níveis de bem-estar subjectivo já que este é um constructo de satisfações emocionais de prazer e de sentimentos de gratificação e envolvimento total, e os professores revelam-nos emoções negativas e a quase inexistência de situações de gratificação ou envolvimento total com a prática docente. Se temos um grupo profissional, que tem uma fundamental importância no desenvolvimento humano, com um quadro de bem-estar negativo, então algo está perigosamente em risco no ensino e na saúde, tanto para alunos, como para professores, e ainda para as famílias portuguesas. O que poderá inverter este cenário pode estar encerrado no facto fundamental do bem-estar subjectivo ser tanto um processo reactivo, como proactivo, ou seja, consegue-se viver bem-estar subjectivo porque há competências individuais de gestão de dificuldades mas também porque se desenvolvem capacidades intrínsecas ao indivíduo, de sentir bem-estar e fazer desse sentimento parte de si mesmo.

(Que relação estabelecem os professores entre o bem-estar subjectivo e a satisfação profissional?)

Apurar o tipo de relações que os professores estabelecem entre dois constructos da natureza do bem-estar subjectivo e da satisfação, ambos em função do exercício da profissão, não foi exactamente um dos resultados conseguidos com o presente estudo.

A combinação a que nos referimos entre identidade individual e papel profissional reforça reciprocidades entre bem-estar com o desempenho profissional e uma vida feliz. E alerta-nos, ainda, para um novo paradigma social em que a realidade profissional se desenrola dinamicamente em profunda interacção com todos os outros domínios da realidade de um indivíduo. Assim, por um lado, fica claro que a satisfação profissional, pela sua multidimensionalidade, se estende para dentro do processamento da satisfação com a vida em geral e, por outro lado, que a satisfação profissional recebe as disposições positivas individuais para a vida em geral.

Portanto, constatamos que os professores relacionam estreitamente o seu bem-estar subjectivo, onde cabe a satisfação com a vida em geral, com a sua satisfação profissional. Os critérios referentes à actividade profissional, as recompensas que a profissão traz ao indivíduo e as relações afectivas que transbordam da profissão para a vida global, são experiên- 
cias mais ou menos satisfatórias dependendo da significação que cada indivíduo lhe conferir. E esta significação surge negativa no nosso estudo transformando a vida dos professores, numa mistura pouco saudável para as pessoas, independentemente da sua profissão, mas de certeza para os profissionais da docência. Consideramos que a elasticidade de fronteiras entre dimensões humanas, para o Homem moderno, trás reforços de competências e de habilidades para a sobrevivência e para as vivências absolutamente necessárias ao seu desenvolvimento que é de formação sub-especializada. Mas se passamos de flexibilidade para uma amalgama caótica que não permita a ninguém defender papéis diferentes, em função dos múltiplos requisitos, e que influencia toda a vida quando alguma polarização negativa acontece, como no presente é a situação profissional dos docentes, então só podemos dizer que há que aprender a distinguir dimensões cognitivas e subjectivas e reconhecer fronteiras dimensionais, já que o enquadramento da vida humana se desenrola numa matriz viva de interacções, não sendo provável escusar-se para outra qualquer fórmula vivencial.

\section{Conclusão}

Os dados do presente estudo permitem-nos apontar as seguintes conclusões sobre a forma como os professores de Ensino Secundário vivem a sua profissão em Portugal:

1. Identificámos percepções emocionalmente negativas e grandes dificuldades para referenciar emoções positivas, o que revela níveis baixos de bem-estar subjectivo

2. Os professores fazem, globalmente, juízos avaliativos negativos sobre a satisfação com a profissão docente

3. Não é possível falar de níveis de bem-estar subjectivo já que este é um constructo de satisfações emocionais, de prazer e de sentimentos de gratificação e envolvimento total

4. Os professores revelam emoções negativas e a quase inexistência de situações de gratificação ou envolvimento total com a prática docente

5. Há indícios de baixo investimento e empenhamento nos factores que aumentam o saber com a profissão

6. Os professores relacionam estreitamente a satisfação com a vida em geral com a sua satisfação profissional

7. Sendo este grupo profissional fundamental para o desenvolvimento humano, como não se sentem satisfeitos com a sua profissão, podemos estar face a um risco no ensino e na saúde para alunos, professores e para as famílias portuguesas

Aceitando a satisfação como uma característica predisposicional individual e que se generaliza partindo duma avaliação positiva com a vida e influenciando o desempenho profissional, temos que afirmar a necessidade dos professores terem bem clara a sua identidade individual e o seu papel profissional, no que respeita a limites, para que a contaminação ou indistinção identitária não ponha em causa o bom e satisfatório desempenho profissional. Parece-nos que os professores modernos devem querer e gostar de o ser (devem ter características intrínsecas de empatia, motivação para partilhar saberes, capacidade para gerir conflitos relacionais e disposição emocional positiva, no que diz respeito à sua identidade individual) e desenvolver a profissão num verdadeiro substrato pedagógico (necessitam de reconhecimento socioprofissional, motivação extrínseca e legislação facilitadora da for- 
mação de sujeitos autónomos e independentes), para que os resultados, à escala macro-social ou do ponto de vista individual, sejam de satisfação. Nesta perspectiva poderíamos descrever o seguinte modelo:

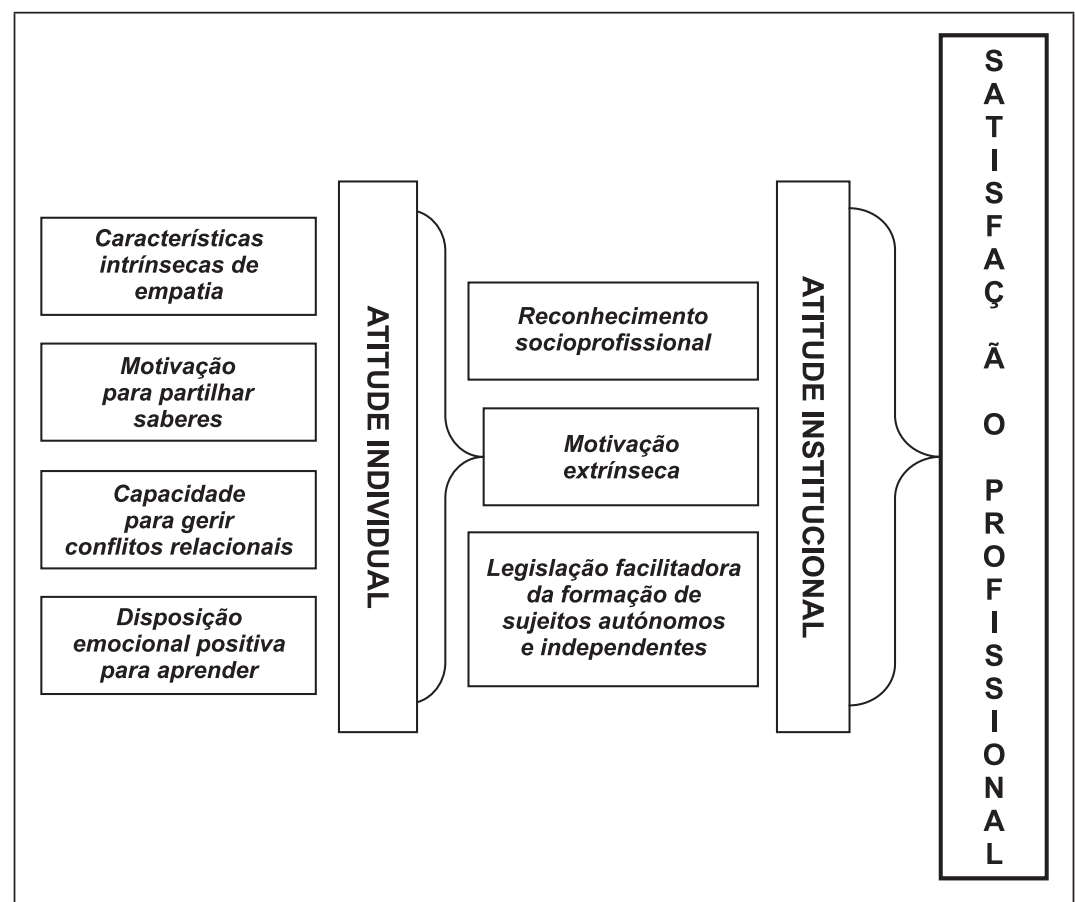

MODELO 1. Actitudes individuales y institucionales promotoras de satisfacción en profesiones de sustrato emocional.

Então, parece-nos que os professores estão duplamente prisioneiros no desempenho da sua profissão e impedidos de sentir satisfação e bem-estar: de si mesmos e do sistema educativo vigente. Como estão estes profissionais a gerir a sua carreira que não vêem que a instituição está a crescer mal? Como e com quê estão os professores a comparar a sua vida profissional real que sentem defraudados os seus ideais? Confraternizámos com o risco desta profissão de substrato emocional se abafar por falta de sapiens e de doctus e só lhe restar um peritus. Um risco que não é só dos professores mas é de todos nós. Descrevemos, explicámos, avaliámos e definimos um perfil mas só conseguimos afirmar mais uma vez que os professores não falam de satisfação com a mesma facilidade com que o fazem sobre as suas insatisfações. Defeito cultural ou crise social?

\section{Referências bibliográficas}

Albuquerque, A. \& Tróccoli, B. (2004). Desenvolvimento de uma Escala de Bem-estar Subjectivo. Psicologia: Teoria e Pesquisa, vol. 20, 2, 153-164. 
Beutell, N. (2006). Life satisfaction. In Casey, J. \& Sweet, S. (Eds) Work-Family Encyclopedia, Sloan Work and Family Research Network. Boston College: Massachusetts. Disponível em: http://www.wfnetwork.bc.edu/encyclopedia.php?mode=nav\&area=academics Acesso em: 20/06/2006

Buitrago, J. P. (2006). El nuevo modelo de profesor: un análisis crítico, Editorial La Muralla, SA: Madrid.

Carochinho, J-A. (2006). Tradução, adaptação e validação de escala de bem-estar psicológico (EBP). Comunicação apresentada na XI Conferência Internacional Avaliação Psicológica: Formas e Contextos, Braga, Universidade do Minho.

Carruthers, C. (2004). "The power of the positive: Leisure and well-being". Therapeutic Recreation Journal, Second Quarter 2004.

Chu, K. (2002). The effects of emotional labour on employee work outcomes. Dissertation submitted to the faculty of the Virginia Polytechnic Institute and State University for the degree of Doctor of Philosophy in Hospitality and Tourism Management, Blacsksburg, Virginia, U.S.A.

Diener, E., Lyubomirsky, S. \& King, L. (2005). "The benefits of frequent positive affect: does happiness lead to success?" Psychological Bulletin, vol 131, n 6, 803-855.

Delle Fave, A. (2006). Dimensions of Well-Being, Research and Intervention. FrancoAngeli: Milão. Hill, M. M. \& Hill, Andrew. (2000) Investigação por questionário. Edições Sílabo: Lisboa.

Jesus, S. N. (1998). Bem-estar dos professores. Estratégias para a realização e desenvolvimento profissional. Porto: Porto Editora.

Loureiro, C. (2001). A docência como profissão - culturas dos professores e a (in) diferenciação profissional. Edições Asa: Lisboa.

Marujo, H. A. \& Neto, L. M. (2001). Educação Emocional e Optimismo. Lisboa: Editorial Presença.

Marujo, H. A., Neto, L. M. \& Perloiro, M. F. (2003). Pedagogía del Optimismo. Guía para lograr ambientes positivos y estimulantes. Narcea Ediciones: Madrid.

Nóvoa A. (org) (1999). Profissão professor. Porto Editora: Porto.

Seligman, M. (2002). Authentic Happiness: using the new positive psychology to realize your potential for lasting fulfilment. The Free Press: N. Y.

Pedro, N. \& Peixoto, F. (2006). "Satisfação profissional e auto-estima em professores dos $2^{\circ}$ e $3^{\circ}$ ciclos do Ensino Básico". Análise Psicológica, 2 (XXIV): 247-262.

Rijavec, M. (2006) "Extrinsic vs. intrinsic life goals, psychological needs and life satisfaction", in Della Fave, A., Dimensions of well-being, 91-103.

Seco, G. M. (2002) A satisfação dos professores - teorias, modelos e evidências, Edições Asa: Lisboa.

Seligman, M. (2000) Psicologia positiva. Psicologia-positiva.com. Disponível em: http://www.psicologia-positiva.com/Acesso em 02/04/2005.

Simões, A., Ferreira, J. A., Lima, M. P., Pinheiro, M. R., Vieira, C. M., Matos, A. P. \& Oliveira, A. L. (2000). "O bem-estar subjectivo: Estado actual dos conhecimentos". Psicologia, Educação e Cultura, vol. IV, 243-280.

Soares, A. (2003). Tears at work: gender, interaction and emotional labour. Just Labour, vol. 2 (Spring 2003), 36-44.

Trigo-Santos, F. (1996). Atitudes e crenças dos professores do ensino secundário - satisfação, descontentamento e desgaste profissional. Instituto de Inovação Educacional: Lisboa.

Fecha de recepción: 09-05-08

Fecha de revision: 05-09-08

Fecha de aceptación: 10-09-08 